\title{
Excess androgen production in subcutaneous adipose tissue of women with polycystic ovarian syndrome is not related to insulin or LH
}

\author{
Saad A Amer, Nadia G Alzanati, Avril Warren, Rebecca Tarbox and Raheela Khan \\ Division of Medical Sciences \& Graduate Entry Medicine, University of Nottingham, Royal Derby Hospital, Derby, UK \\ Correspondence should be addressed to S A Amer: saad.amer@nottingham.ac.uk
}

\begin{abstract}
The purpose of this study was to investigate androgen production and the role of insulin and LH in its regulation in subcutaneous adipose tissue (SAT) of women with polycystic ovarian syndrome (PCOS). Protein and mRNA expression of androgen synthesis enzymes (cytochrome P450 17A1 (CYP17A1) and aldo-keto reductase 1C3 (AKR1C3)) were measured in SAT biopsies from women with PCOS, diagnosed according to the Rotterdam criteria $(n=15)$ and healthy controls $(n=15)$. Cultured mature adipocytes (differentiated from SAT biopsies) were treated with insulin \pm phosphoinositol-3-kinase inhibitor (LY294002) or $\mathrm{LH} \pm$ insulin. CYP17A1 and AKR1C3 mRNA expression and testosterone concentrations were measured in treated and untreated adipocyte cultures. AKR1C3 mRNA was significantly $(P<0.001)$ greater in PCOS vS non-PCOS SAT, but CYP17A1 was not significantly different between the two groups. AKR1C3 and CYP17A1 protein expression was not significantly different in PCOS vs non-PCOS SAT. In untreated adipocyte cultures, CYP17A1, AKR1C3 and testosterone levels were significantly higher in the PCOS vs the non-PCOS groups. Addition of insulin increased AKR1C3 mRNA and testosterone levels, but not CYP17A1 mRNA in non-PCOS with no effect on PCOS adipocytes. The stimulatory effects of insulin were not inhibited by LY294002. Addition of LH increased CYP17A1, AKR1C3 and testosterone in non-PCOS adipocytes with no effect in PCOS adipocytes. In conclusion, SAT of women with PCOS produces excess androgen, which may contribute to PCOS-related hyperandrogenaemia. This SAT androgen excess is independent of obesity and is not directly stimulated by inulin or LH.
\end{abstract}

\author{
Key Words \\ - polycystic ovarian \\ syndrome \\ - adipose tissue \\ - hyperandrogenism \\ - CYP17A1 \\ - AKR1C3 \\ - hyperinsulinaemia
}

\section{Introduction}

Polycystic ovarian syndrome (PCOS) is the most common ovarian endocrinopathy with a prevalence of $6-10 \%$ based on National Institutes of Health (NIH) criteria (Fauser et al. 2012) and 17\% according to Rotterdam consensus criteria (Lauritsen et al. 2014). It accounts for $83 \%$ of anovulatory infertility (Kousta et al. 1999) and $89 \%$ of hyperandrogenism (Elhassan et al. 2018). It is characterised by a varied combination of clinical (anovulation and hyperandrogenism), biochemical (excess serum luteinizing hormone (LH) and androgen concentrations) and ovarian morphological (polycystic ovaries) features. PCOS is well known to negatively affect the quality of life and psychological wellbeing of women (Li et al. 2011) and is associated with significant long-term metabolic and cardiovascular morbidities (Fauser et al. 2012). 
Despite its high prevalence, the underlying mechanisms of PCOS remain largely uncertain. It is well established that androgen excess plays a central role in PCOS pathogenesis. Current evidence suggests three main cellular sources for this androgen excess including ovarian theca cells (Gilling-Smith et al. 1997), adrenal cortical cells (Kumar et al. 2005) and adipocytes (Rosenfield et al. 2011, O'Reilly et al. 2017). Aldo-keto reductase 1C3 (AKR1C3), also known as 17 $\beta$-hydroxysteroid dehydrogenase type 5 (17 $\beta$-HSD5), has been reported as the predominant androgen biosynthesis enzyme in adipose tissue that converts androstenedione to testosterone (Quinkler et al. 2004). Recent research has shown evidence of increased SAT AKR1C3 mRNA expression (Wang et al. 2012, O'Reilly et al. 2017) and increased intra-adipose concentrations of testosterone in women with PCOS (O'Reilly et al. 2017). AKR1C3 expression and activity in omental adipose tissue were found to correlate positively with adiposity (Blouin et al. 2005). Furthermore, simple obesity has been associated with increased androgen production in reproductive age women (Samojlik et al. 1984, Kirschner et al. 1990). Therefore, it remains to be determined whether increased adipose tissue AKR1C3 expression in PCOS women is independent of obesity.

Although hyperinsulinaemia (due to insulin resistance) and hyperandrogenaemia are closely linked and positively correlated in PCOS women, the exact interaction between them remains unclear. Recently, O'Reilly and coworkers reported that insulin significantly increased AKR1C3 mRNA expression in differentiated subcutaneous adipocytes and increased testosterone generation in cell media from cultured subcutaneous adipocytes from non-PCOS women (O'Reilly et al. 2017). Currently, there are no data on insulin actions in adipose tissue of PCOS women. Furthermore, there are no data on the mechanisms of insulin-mediated effects on androgen production in adipocytes of women with or without PCOS. Currently, there are only limited and conflicting data on the mechanisms of insulin actions in theca cells. One study involving theca cells from normal ovaries has suggested phosphatidylinositol-3-kinase (PI-3K) as a possible insulin signalling mediator for insulin stimulatory effects on CYP17 (Munir et al. 2004). On the other hand, the insulin-mediated increase in steroidogenesis in granulosa lutein cells of normal ovaries was independent of the PI-3K pathway (Poretsky et al. 2001). Therefore, the role of the PI-3K pathway in normal and polycystic ovaries remains uncertain. Another area of uncertainty is whether insulin alone is capable of stimulating androgen synthesis or requires LH-induced cAMP activation. Currently there are only few and conflicting data on the interaction between insulin and LH in ovarian tissue (Nestler et al. 1998, Munir et al. 2004) with no data for adipose tissue.

Based on the above, we hypothesised that hyperinsulinaemia with or without excess LH in women with PCOS could augment androgen production in peripheral adipose tissue through a mechanism involving the PI-3K insulin signalling pathway. This hypothesis has never previously been tested in PCOS. The aim of this in vitro study was to measure the expression of the main androgen-synthesizing enzymes (AKR1C3 and cytochrome P450 17A1 (CYP17A1), also called $17 \alpha$-hydroxylase, 17,20-lyase) in SAT from women with and without PCOS. We also measured the expression of these enzymes and testosterone concentrations in mature adipocyte cultures (prepared from SAT) incubated with different concentrations of insulin \pm PI-3K inhibitor (LY294002) or LH \pm insulin.

\section{Methods}

This study was approved by the Derbyshire Ethics Committee (Ref: 09/H0401/27) and all participants gave written informed consent.

\section{Subjects}

The study included a group of PCOS women and a control group of age- and BMI-matched healthy women who were scheduled to undergo elective gynaecological surgery at Royal Derby Hospital. All participants were of reproductive age (20-45) with a BMI of $20-35 \mathrm{k} / \mathrm{m}^{2}$.

PCOS was diagnosed according to Rotterdam consensus criteria, by at least two of the following three features: (1) oligo-/anovulation, (2) clinical and/or biochemical hyperandrogenaemia (testosterone $\geq 2.5 \mathrm{nmol} / \mathrm{L}$ or FAI $\geq 5 \%$ ) or (3) sonographic appearance of polycystic ovaries (Rotterdam ESHRE/ASRM-Sponsored PCOS Consensus Workshop Group 2004).

Healthy controls (non-PCOS) included women with regular menstrual cycles, normal serum testosterone levels $<2.5 \mathrm{nmol} / \mathrm{L}$ and normal FAI $<5 \%$.

Exclusion criteria were endocrine or metabolic disorders for example thyroid disease, diabetes or hyperprolactinaemia, concurrent hormonal therapy for example contraceptive pill, anti-androgenic medication and corticosteroids or any weight loss medicines. Women unable to provide written informed consent were excluded. 


\section{Adipose tissue biopsies}

Approximately $5 \mathrm{~g}$ of subcutaneous adipose tissue (SAT) samples were obtained from abdominal incisions during elective gynaecological procedures including ovarian drilling, salpingectomy, myomectomy and diagnostic laparoscopy. The biopsy was divided into two parts, one immediately snap frozen and stored at $-80^{\circ} \mathrm{C}$ until use for expression analyses. The second part was transferred into a sterile container containing Hanks' balanced salt solution (HBSS) for primary cell culture on the same day.

\section{SAT primary cell culture}

These were prepared as described in our previous publication (Cadagan et al. 2014). Briefly, SAT biopsies were cut into small pieces and enzymatically dispersed using collagenase $(1 \mathrm{mg} / \mathrm{mL})$ prepared in divalent cationfree HBSS. The preparation was incubated at $37^{\circ} \mathrm{C}$ for no more than $60 \mathrm{~min}$ and then filtered through a $250 \mu \mathrm{m}$ nylon mesh. This resulted in a solution with two phases with the lower phase containing the stromal vascular fraction which includes preadipocytes. The lower phase was removed and centrifuged at $100 \mathrm{~g}$ for $5 \mathrm{~min}$. The pellet (containing preadipocytes) was collected and resuspended in high glucose $(4500 \mathrm{mg} / \mathrm{L})$ Dulbecco's minimum essential medium (DMEM) supplemented with $10 \%$ foetal bovine serum and 1\% penicillin/streptomycin for culturing in a separate T25flask. Cells were maintained at $37^{\circ} \mathrm{C}$ in an air $/ 5 \% \mathrm{CO}_{2}$ environment, until confluent (4-6 days).

To initiate in vitro differentiation into mature adipocytes, preadipocytes were seeded at a density of $3 \times 10^{5} \mathrm{cells} / \mathrm{mL}$ in a 24 -well plate. Differentiation was induced (Day 0 ) with the addition of a hormone cocktail (denoted IDM) comprising $50 \mathrm{nM}$ insulin, $0.25 \mathrm{mM}$ 3-isobutyl-1-methylxanthine (IBMX) and $100 \mathrm{nM}$ dexamethasone. After 2 days, IDM was replaced with maintenance differentiation medium (MDM), similar to IDM but without IBMX. Triacylglycerol droplets became visible on Day 5 and cells were fully differentiated into adipocytes on Day 14. For negative controls, cells were maintained in DMEM containing FBS alone.

In vitro differentiated mature adipocytes were kept for $24 \mathrm{~h}$ in serum-free DMEM to prepare for the experiments. The cultures were then either left untreated (controls) or incubated for $72 \mathrm{~h}$ with insulin $(1,10,100 \mathrm{nM}) \pm \mathrm{LY} 294002$ $(1 \mu \mathrm{g} / \mathrm{mL})$ or $\mathrm{LH}(10 \mathrm{nmol} / \mathrm{mL}) \pm$ insulin $(1,10,100 \mathrm{nM})$. The culture media were then removed from each well and testosterone concentrations were measured by a competitive ELISA using acetylcholinesterase (AChE)

\begin{tabular}{|lr}
\hline $\begin{array}{l}\text { https://joe.bioscientifica.com } \\
\text { https://doi.org/10.1530/JOE-18-0674 }\end{array}$ & (c) 2019 Society for Endocrinology \\
Published by Bioscientifica Ltd. \\
Printed in Great Britain
\end{tabular}

according to the manufacturer's instructions (Cayman Chemicals). This assay is based on the competition between testosterone and the testosterone AChE tracer for the antiserum-binding sites and is inversely proportional to the concentration of antigen in the well. The assay was carried out by the addition of $50 \mu \mathrm{L}$ of testosterone standards $(3.9-500 \mathrm{pg} / \mathrm{mL})$, cell culture supernatants and media blanks, to precoated wells in a 96-well plate. Also included were wells for total activity and non-specific binding and all were carried out in duplicate. The plate was then incubated at $37^{\circ} \mathrm{C}$ for 2 hours, after which the wells were emptied and washed 5 times. Then, Ellman's reagent $(200 \mu \mathrm{L})$ was added to each well and the plate incubated (60-90 min) in the dark, with shaking before reading at $405 \mathrm{~nm}$. Cells remaining in wells were washed, harvested and stored at $-80^{\circ} \mathrm{C}$ for qRT-PCR.

\section{RNA isolation and qRT-PCR}

Frozen SAT biopsies (100-120 mg) were homogenised (Janke and Kunkel, IKA Labortechnik, Germany) in TRI Reagent (Sigma Aldrich). The homogenate was then transferred to an Eppendorf tube and centrifuged at $12,000 \mathrm{~g}$ for $15 \mathrm{~min}$. The resulting fat layer overlying the homogenate was removed to avoid any carryover. Chloroform was then added to the homogenate $(0.2 \mathrm{~mL}$ of chloroform for every $1 \mathrm{ml}$ TRI Reagent), mixed thoroughly by manual shaking for $15 \mathrm{~s}$, incubated at room temperature for $3 \mathrm{~min}$ then centrifuged for $15 \mathrm{~min}$ at $12,000 \mathrm{~g}$ at $4^{\circ} \mathrm{C}$. The resulting upper aqueous layer containing RNA was transferred to a new RNAse-free $1.5 \mathrm{~mL}$ microcentrifuge tube. Total RNA was precipitated with isopropyl alcohol followed by incubation at room temperature for $10 \mathrm{~min}$ and then centrifugation at $12,000 \mathrm{~g}$ for $10 \mathrm{~min}$ at $4^{\circ} \mathrm{C}$. The RNA pellet produced was washed with $75 \%$ ethanol, centrifuged at $7500 \mathrm{~g}$ for $5 \mathrm{~min}$ at $4^{\circ} \mathrm{C}$ before dissolving the RNA pellet in RNase-free water.

Total RNA from cultured mature adipocytes was extracted as described earlier except that TRI Reagent was added at $1 \mathrm{~mL}$ for every $10 \mathrm{~cm}^{2}$ of the culture plate and cells lysed directly.

Reverse transcription was carried out using the HighCapacity cDNA Reverse Transcription Kit with RNAse inhibitor (Applied Biosystems); 1200 ng of total RNA was used to produce $20 \mu \mathrm{L}$ of cDNA. Reverse transcription was performed at $25^{\circ} \mathrm{C}$ for $10 \mathrm{~min}, 37^{\circ} \mathrm{C}$ for $2 \mathrm{~h}$ and $85^{\circ} \mathrm{C}$ for $5 \mathrm{~min}$. Each reaction was performed in duplicate: one containing the reverse transcriptase (+RT) and other one without RT (-RT) in which reverse transcriptase was substituted with water. 
qRT-PCR for CYP17A1 (17,20 alpha hydroxylase) and $A K R 1 C 3$ (17B HSD5) was performed alongside three selected reference genes (GAPDH, ACTB and LRP10). The assay was performed using $2 \mu \mathrm{L}$ cDNA template and $18 \mu \mathrm{L}$ TaqMan Universal PCR Master Mix (Applied Biosystems) containing the specific TaqMan expression assay for the selected gene (Applied Biosystems). Each reaction was carried out in triplicate on $+\mathrm{RT}$ samples, and $-\mathrm{RT}$ samples as well as a no template control (NCT). qPCR was carried out on a Chromo 4 (BioRad) utilising an initial denaturation step at $95^{\circ} \mathrm{C}$ for $10 \mathrm{~min}$, followed by 40 cycles of $95^{\circ} \mathrm{C}$ for $15 \mathrm{~s}$ and $60^{\circ} \mathrm{C}$ for $1 \mathrm{~min}$ for annealing and extension. At the end of each cycle the plate was read and fluorescence intensity was recorded.

The efficiency and optimization of the qRT-PCR reaction was evaluated by generating standard curves for three selected reference genes and target genes using a 10 -fold dilution of a cDNA template. Each dilution was assayed in triplicate. PCR was carried out on a Chromo 4TM System (BioRad).

\section{Western blot (WB) for AKR1C3 and CYP17A1 proteins}

Western immunoblot analysis of AKR1C3 and CYP17A1 protein expression in non-PCOS $(n=7)$ and PCOS $(n=4)$ patients was carried out by extracting total proteins from frozen SAT samples as previously described (Cadagan et al. 2014). Proteins were electrophoresed on $12 \%$ SDS-PAGE and transferred to nitrocellulose membranes by electroblotting. Following blocking with 5\% Marvel in TBS, immune detection of AKR1C3 and CYP17A1 proteins was performed by incubating overnight with rabbit antihuman AKR1C3 polyclonal antibodies (Antibody Registry ID, AB_2753336) a 1:1000 dilution or CYP17A1 (ID, AB_1603486), at a 1:100 dilution. After further washing, goat anti-rabbit IgG secondary antibody conjugated with alkaline phosphatase was added to blots that were left to incubate at room temperature for $2 \mathrm{~h}$ with gentle rocking. Molecular weight markers were used to facilitate protein size detection. Visualisation of bands was carried out using Immunstar reagent (BioRad) and Chemidoc V4.2 (BioRad). Each blot was then stripped and re-probed using $\beta$-actin to control for loading of the protein. Protein was quantified by densitometry and relative expression levels adjusted for $\beta$-actin.

\section{Data analysis}

qRT-PCR data were expressed as comparative threshold (Ct) values and analysed using GenEx software. The mean

(c) 2019 Society for Endocrinology Published by Bioscientifica Ltd. Printed in Great Britain delta $\mathrm{Ct}(\Delta \mathrm{Ct})$ was calculated by using the Ct method to compare the relative amount of the target sequence to the values of the chosen reference genes (Vandesompele et al. 2002). The two-tailed, unpaired $t$-test was used to compare expression levels of target genes in SAT of PCOS and non-PCOS groups.

For ELISA data, values obtained were interpolated against the standard curve to determine the testosterone concentration. Student's unpaired $t$-test was used to compare between the PCOS and non-PCOS groups. Comparison of multiple means was performed using oneway ANOVA with post hoc comparisons employing Tukey's test. Statistical significance was considered when $P<0.05$. Data are expressed as mean \pm s.E.M.

\section{Results}

Table 1 shows characteristics of the study participants inclining PCOS women $(n=15)$ and age- and BMI-matched healthy controls $(n=15)$.

\section{Reference genes}

Of the reference genes tested, GAPDH, ACTB and LPR10 were consistently expressed and stable across PCOS and non-PCOS groups with no statistically significant $(P>0.05)$ difference between the two groups.

\section{CYP17A1 and AKR1C3 mRNA expression in SAT}

CYP17A1 and AKR1C3 mRNA were expressed in SAT of both non-PCOS $(n=8)$ and PCOS $(n=8)$ women (Fig. 1$)$. $A C T B, G A P D H$ and LPR10 were the references genes used to normalise gene analysis. Data analysis showed no statistically significant $(P>0.05)$ difference in CYP17A1 mRNA in PCOS $(12.25 \pm 4.31)$ vs non-PCOS $(8.40 \pm 4.53)$ SAT (Fig. 1A). On the other hand, AKR1C3 mRNA expression in PCOS SAT $(15.12 \pm 2.00)$ was significantly $(P<0.001)$ higher than that $(3.30 \pm 1.03)$ of the non-PCOS SAT (Fig. 1B).

Table 1 Demography of all women included. Data summarised as median (range) and mean \pm S.E.M.

\begin{tabular}{|c|c|c|c|}
\hline Parameter & Non-PCOS $(n=15)$ & $\operatorname{PCOS}(n=15)$ & $P$ value \\
\hline Age (year) & $32.4(25-45)$ & $30.5(24-36)$ & NS \\
\hline $\mathrm{BMI}\left(\mathrm{kg} / \mathrm{m}^{2}\right)$ & $27.5(20.0-32.2)$ & $29.4(20.9-31.62)$ & NS \\
\hline $\begin{array}{l}\text { Testosterone } \\
\text { (nmol/L) }\end{array}$ & $1.5 \pm 0.2$ & $2.4 \pm 0.5$ & 0.03 \\
\hline LH (nmol/L) & $7.8 \pm 1.4$ & $29.8 \pm 19.2$ & $<0.01$ \\
\hline
\end{tabular}




\section{AKR1C3 and CYP17A1 protein expression in SAT}

Western immunoblotting showed expression at $36 \mathrm{kDa}$ and $57 \mathrm{kDa}$ suggestive of the presence of AKR1C3 and CYP17A1 respectively in SAT of both groups (non-PCOS, $n=7$; PCOS, $n=4$ ) (Fig. 1C and D). The relative intensity (normalised to $\beta$-actin) of AKR1C3 and CYP17A1 proteins expression were similar in PCOS compared to non-PCOS. There was no significant difference in the protein expression between non-PCOS and PCOS (AKR1C3, $P=0.6989$; CYP17A1, $P>0.05$ ) (Fig. 1E and F).

\section{CYP17A1 mRNA expression in in vitro differentiated mature adipocytes}

Figure 2 shows CYP17A1 mRNA expression in untreated and hormone-treated mature adipocyte cultures prepared from SAT of PCOS $(n=5)$ vs non-PCOS $(n=5)$ women. The expression in untreated adipocytes was significantly $(P<0.0001)$ higher in PCOS $(17.98 \pm 1.30)$ vs non-PCOS $(1.12 \pm 0.17)$ adipocytes (Fig. 2). Addition of increasing concentrations of insulin $(1,10$, and $100 \mathrm{nM})$ to the adipocyte cultures did not result in any statistically significant $(P>0.05)$ change in the CYP17A1 mRNA expression in either of the two groups (Fig. 2A). On the other hand, addition of $\mathrm{LH}(10 \mathrm{nmol} / \mathrm{L})$ resulted in a statistically significant $(P<0.001)$ increase in $C Y P 17 A 1$
mRNA expression in non-PCOS, but not in PCOS adipocytes (Fig. 2B). Adding increasing concentrations of insulin with $\mathrm{LH}$ did not have any additional effect on the expression of CYP17A1 mRNA in either of the two groups (Fig. 2B).

\section{AKR1C3 mRNA expression in in vitro differentiated mature adipocytes}

Figure 3 shows AKR1C3 mRNA expressions in untreated and hormone-treated mature adipocytes. The level in untreated mature adipocytes of PCOS women (5.19 \pm 1.27$)$ was significantly $(P=0.01)$ higher than that $(0.97 \pm 0.21)$ of non-PCOS women (Fig. 3). Only insulin at $100 \mathrm{nM}$ resulted in a statistically significant $(P<0.001)$ increase in the expression of $A K R 1 C 3$ mRNA in adipocytes of non-PCOS, but not of PCOS women (Fig. 3A). With regards to the lower insulin concentrations, there was a trend towards a dose-dependent rise in AKR1C3 mRNA expression in non-PCOS adipocytes, but this did not reach statistical significance. Addition of $\mathrm{LH}(10 \mathrm{nmol} / \mathrm{L})$ resulted a significant $(P<0.01)$ increase in $A K R 1 C 3$ mRNA expression in adipocytes of non-PCOS, but not of PCOS women (Fig. 3B). Adding increasing concentrations of insulin with LH did not have any additional effect on the expression of $A K R 1 C 3$ mRNA in either of the two groups.
A

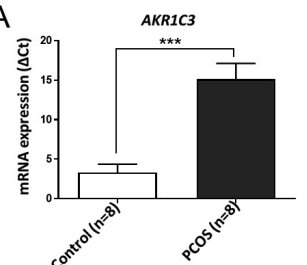

$\mathrm{C}_{\text {мwм }}$
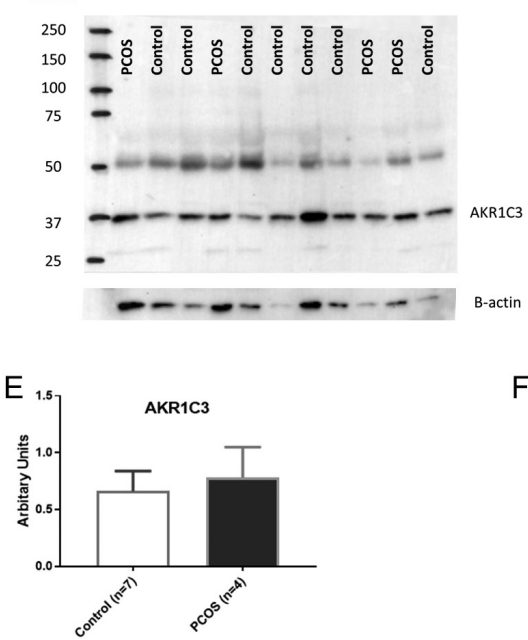

D

$\mathrm{F}$
B

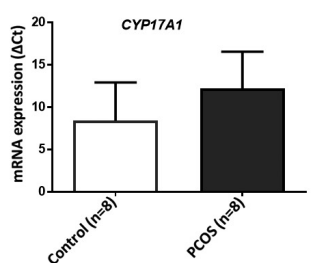

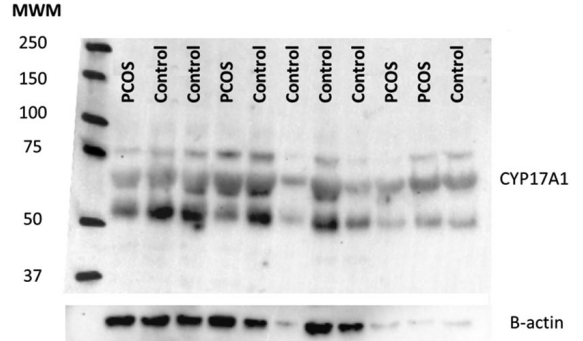

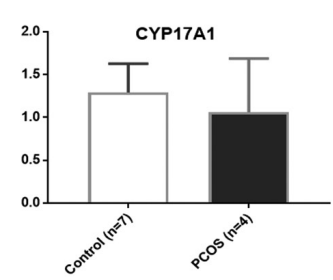

Figure 1

CYP17A1 and AKR1C3 in SAT of PCOS vs non-PCOS women. (A and B) Relative mRNA expression of CYP17A1 an AKR1C3 in SAT from non-PCOS $(n=8)$ vs PCOS $(n=8)$ women. Data expressed as mean \pm S.E.M., analysed with GenEx and compared using the $\Delta C t$ method. (C, D, E and F) Western immunoblot analysis of AKR1C3 and CYP17A1 protein expression in SAT from non-PCOS $(n=7)$ vs PCOS $(n=4)$ women. (C and D) Relative intensity of AKR1C3 and CYP17A1 protein expression. ( $E$ and $F)$ Relative levels of band intensity in WB of AKR1C3 in both groups. Data presented as mean \pm S.E.M. ${ }^{*} \star * P<0.001$. P, PCOS; non-P, non-PCOS; SAT, subcutaneous adipose tissue. 
$A$
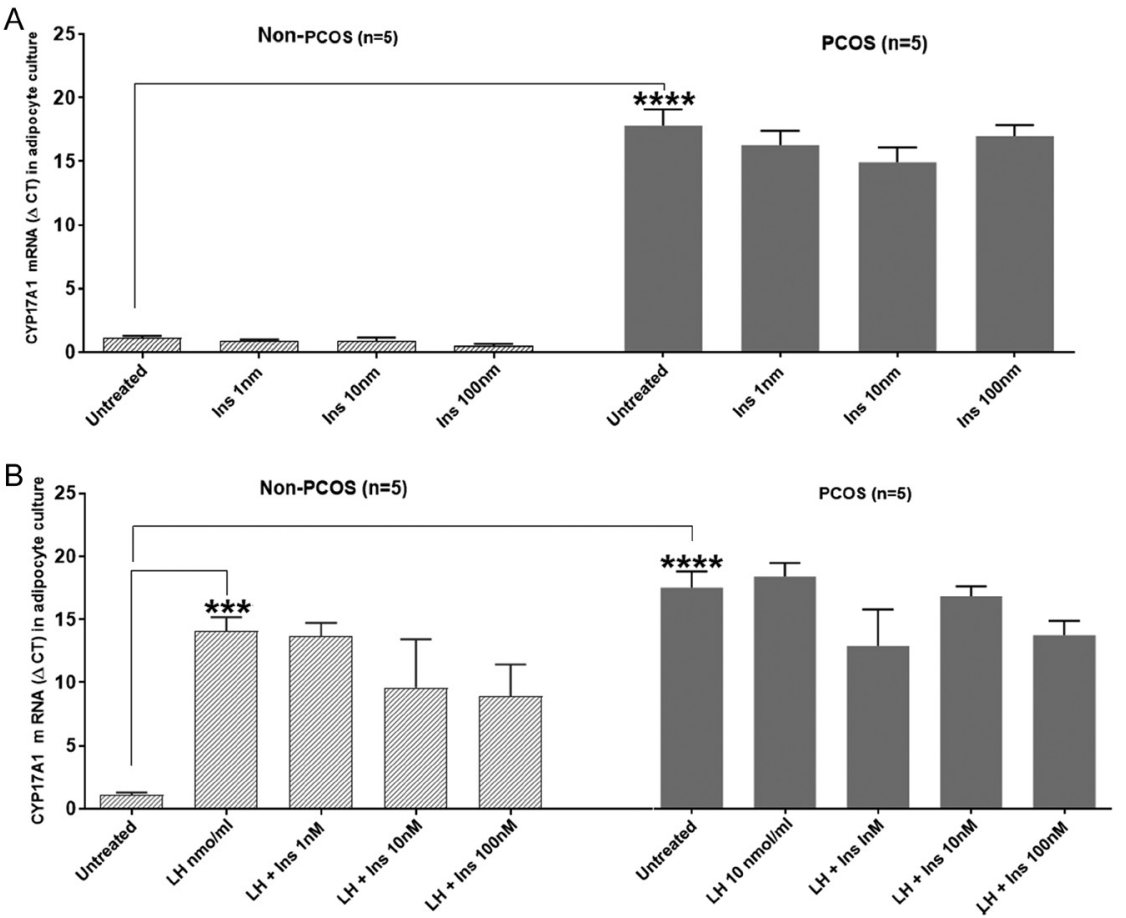

Figure 2

CYP17A1 mRNA expression in untreated and hormone treated mature adipocyte cultures of PCOS $(n=5)$ vs non-PCOS $(n=5)$ women. (A) Expression in adipocytes treated with different concentrations of insulin (1, 10, $100 \mathrm{nM})$. (B) Expression levels in adipocytes treated with $\mathrm{LH}$ $(10 \mathrm{nmol} / \mathrm{mL}) \pm$ different concentrations of insulin $(1,10,100 \mathrm{nM})$. Data presented as mean \pm S.E.M. $\Delta \mathrm{Ct}$ and analysed using one-way ANOVA. Data presented as mean \pm S.E.M. $* * * P<0.001$; $\star * \star \star x<0.0001$.

\section{Testosterone concentration in differentiated adipocytes}

Testosterone concentration in the supernatant of untreated cultured PCOS adipocytes (mean \pm S.E.M., $129.27 \pm 2.54 \mathrm{pg} / \mathrm{mL})$ was significantly $(P<0.0001)$ higher than that $(33.67 \pm 4.56 \mathrm{pg} / \mathrm{mL})$ of non-PCOS adipocytes (Fig. 4). Addition of insulin (1, 10 and $100 \mathrm{nM})$ resulted in a significant dose-dependent increase in testosterone concentrations in non-PCOS adipocyte cultures but had no effect on PCOS adipocytes (Fig. 4A). Adding LH $(10 \mathrm{~nm} / \mathrm{mL})$ to cultured adipocytes had a much more potent effect than insulin with a significant $(P<0.0001)$ increase in testosterone concentration from adipocytes of non-PCOS women $(n=5)$ but had no effect in PCOS adipocytes (Fig. 4B). Addition of increasing insulin

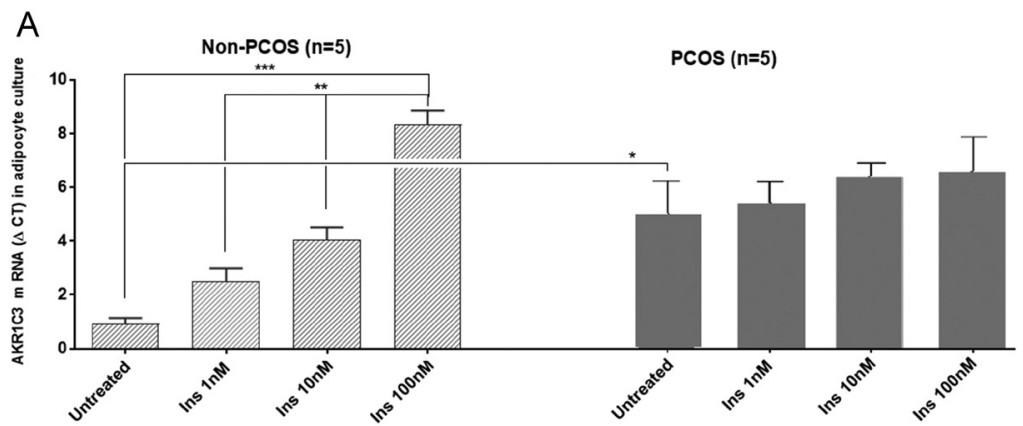

B

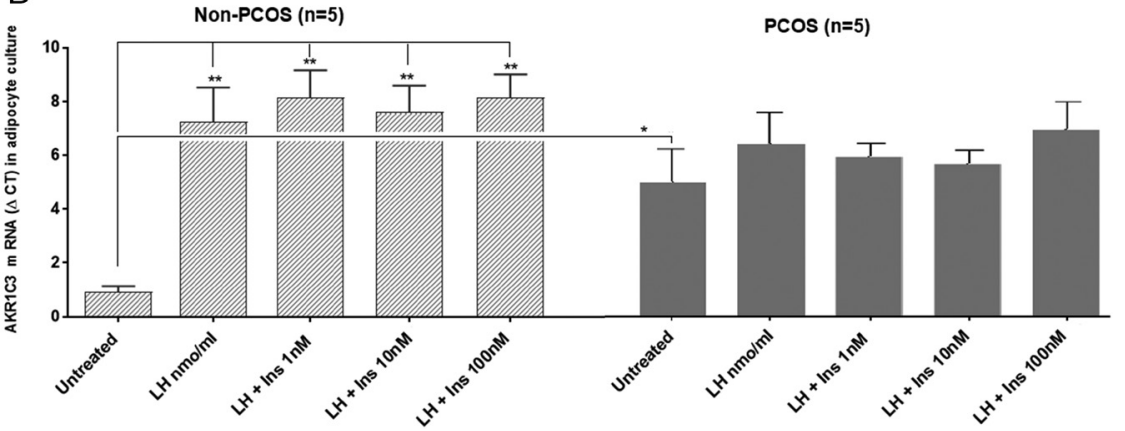

Figure 3

AKRC13 mRNA expression in untreated and hormone treated mature adipocytes of PCOS $(n=5)$ vs non-PCOS ( $n=5)$ women. (A) Expression in adipocytes treated with different concentrations of insulin (1, 10, $100 \mathrm{nM})$. (B) Expression levels in adipocytes treated with $\mathrm{LH}$ $(10 \mathrm{nmol} / \mathrm{mL}) \pm$ different concentrations of insulin $(1,10,100 \mathrm{nM})$. Data presented as mean \pm S.E.M. $\Delta \mathrm{Ct}$ and analysed using one-way ANOVA test. $\star P<0.05 ; * * P<0.01 ; * * * P<0.001$ 


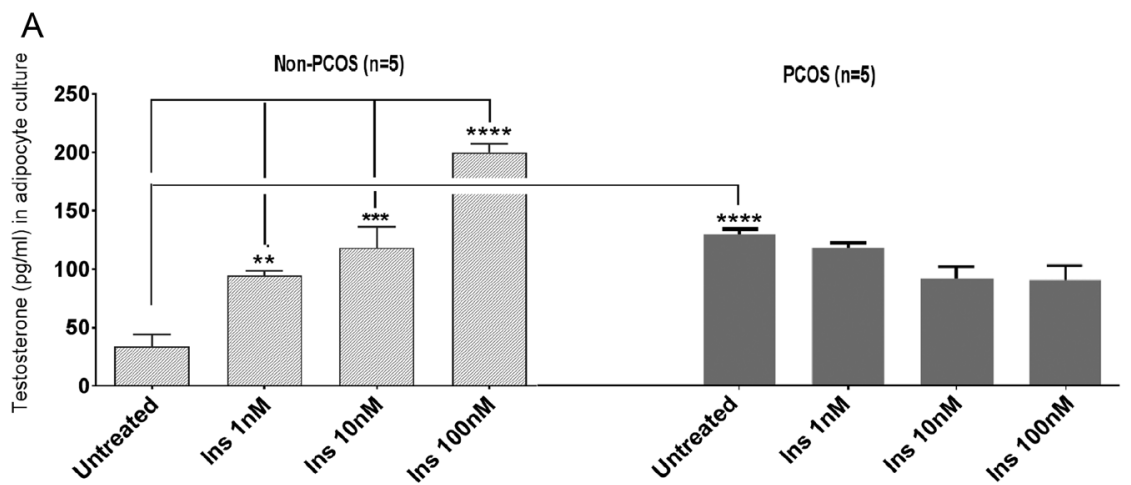

$\mathrm{B}$

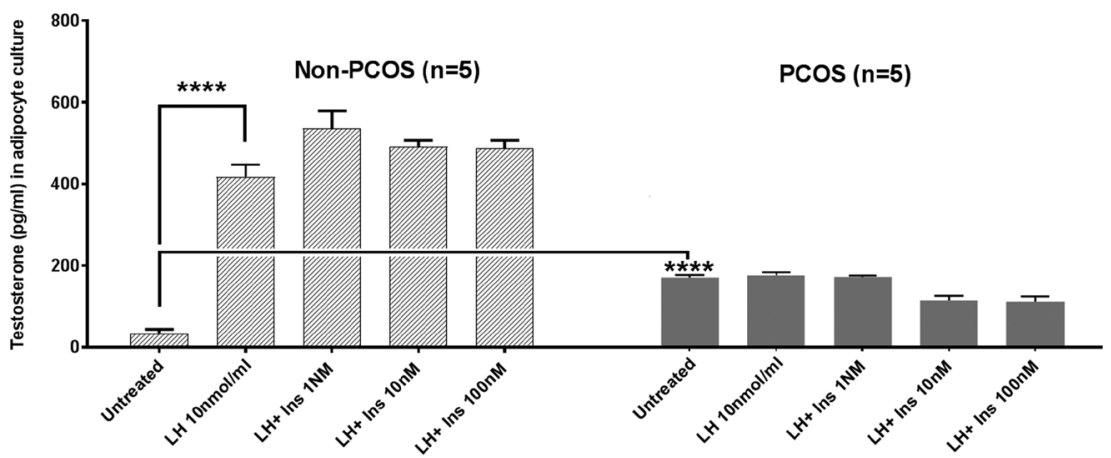

\section{Figure 4}

Testosterone secretion $(\mathrm{pg} / \mathrm{mL})$ by untreated and hormone treated mature adipocytes of PCOS $(n=5)$ vs non-PCOS $(n=5)$ women. (A) Levels in adipocytes treated with increasing concentrations of insulin (1, 10, $100 \mathrm{nM})$. (B) Levels in adipocytes treated with $\mathrm{LH}(10 \mathrm{nmol} / \mathrm{mL}) \pm$ insulin in different concentrations. Data presented as mean \pm S.E.M. and analysed using one-way ANOVA. $* * P<0.01$; $\star \star \star P<0.001 ; * \star \star \star * P<0.0001$.

concentrations to $\mathrm{LH}$ had no additional effect on testosterone concentrations.

\section{The role of PI-3K in insulin-induced augmentation of AKR1C3 and testosterone in non-PCOS adipocytes}

Addition of the PI-3K inhibitor (LY294002, $1 \mu \mathrm{m} / \mathrm{mL}$ ) with increasing concentrations of insulin to cultured nonPCOS adipocytes did not inhibit the stimulatory effect of insulin on $A K R 1 C 3 \mathrm{mRNA}$ expression or testosterone concentration in adipocyte culture (Fig. 5A and B).

\section{Discussion}

In this in vitro study we investigated the dynamics of androgen production and its interactions with insulin and LH in SAT biopsies obtained from women with and without PCOS. To the best of our knowledge, this is the first report on CYP17 expression, insulin actions on CYP17 and AKR1C3 and the role of the PI-3K insulin signalling pathway in adipocytes derived from SAT of PCOS women. The results show upregulated AKR1C3 and CYP171A mRNA expression in SAT and in cultured subcutaneous adipocytes of PCOS women. In addition, testosterone concentrations were markedly higher in cultured adipocytes derived from SAT of PCOS women.
Whilst exposure to insulin had no effect on CYP17A1 mRNA expression, it resulted in a dose-dependent augmentation of $A K R C 13$ expression and testosterone secretion in cultured non-PCOS adipocytes, with no effect on PCOS-cultured adipocytes. These stimulatory effects of insulin are independent of the PI-3K signalling pathway. Notably, LH alone resulted in a marked increase of CYP17A1, AKR1C3 and testosterone levels in non-PCOS, but not in PCOS adipocytes.

In our experiments, we used insulin concentrations of 1,10 and $100 \mathrm{nM}$, which are equivalent to 5.7, 57.3 and $573.4 \mathrm{ng} / \mathrm{mL}$ respectively. These concentrations correspond to physiological $(1-30 \mathrm{ng} / \mathrm{mL})$, moderately supraphysiological (50-100 ng/mL) and markedly supraphysiological (500-1000 $\mathrm{ng} / \mathrm{mL})$ in vivo insulin levels (Poretsky et al. 2001, Munir et al. 2004). The moderately supraphysiological levels represent insulin concentrations in women with PCOS. With regards to the LH concentration, in the absence of any previous similar studies, we used $10 \mathrm{nmol} / \mathrm{L}$, which is thought to mimic in vivo physiological levels. However, our LH experiment should be considered preliminary and future studies should use more accurately measured concentrations to represent in vivo physiological and supraphysiological levels.

As stated above, there are no previous studies on CYP17 mRNA expression in SAT of PCOS women. 

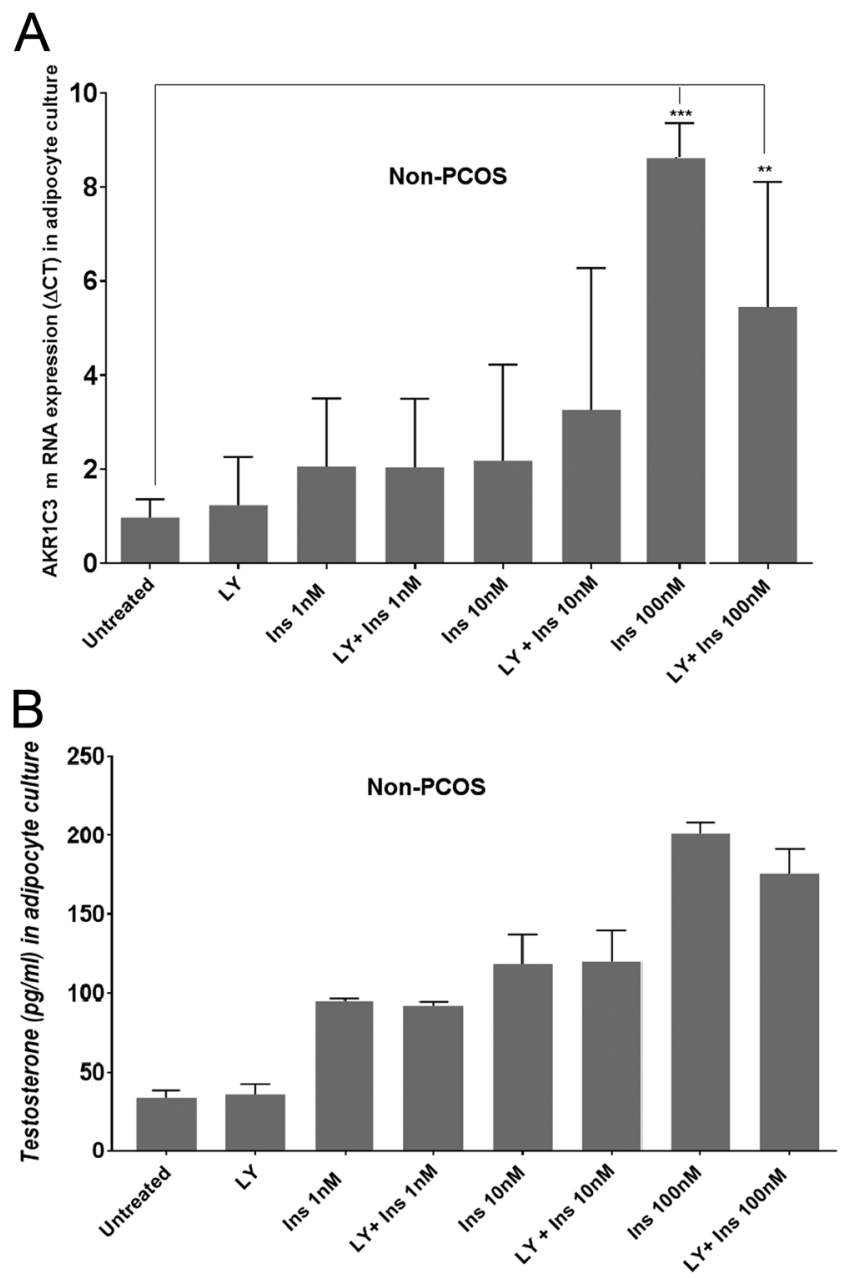

\section{Figure 5}

The role of PI-3K inhibitor (LY294002) in insulin mediated actions in non-PCOS adipocytes $(n=5)$. (A) Expression of AKR1C3 in non-PCOS adipocytes treated with insulin $(1,10,100 \mathrm{nM}) \pm \mathrm{LY} 294002(1 \mu \mathrm{g} / \mathrm{mL})$. (B) Testosterone levels $(\mathrm{pg} / \mathrm{mL})$ in adipocytes treated with insulin $(1,10$, $100 \mathrm{nM}) \pm$ LY294002. Data presented as mean \pm S.E.M. and analysed using one-way ANOVA. ${ }^{* * P}<0.01 ; * \star \star P<0.001$.

Our data are consistent with previous studies on non-PCOS SAT confirming the presence of CYP17 either directly by measuring CYP17 mRNA using qRT-PCR (Puche et al. 2002) or liquid chromatography-tandem mass spectrometry (LC-MS/MS) (Kinoshita et al. 2014) or indirectly by measuring 17-OH-Progesterone and A-dione, which require CYP17 (Feher \& Bodrogi 1982). In contrast, other studies failed to detect CYP17 mRNA in SAT of healthy women (Dalla Valle et al. 2006, Mackenzie et al. 2008, Wang et al. 2012). This may be due to an undetectable CYP17 isozyme or instability of CYP17 in adipose tissue (Kinoshita et al. 2014).

Our SAT AKR1C3 data are consistent with two recent similar studies reporting increased AKR1C3 mRNA expression, measured by qRT-RT in SAT biopsies from PCOS women compared with healthy controls (Wang et al. 2012, O'Reilly et al. 2017).

Our testosterone results are supported by a previous in vivo study by O'Reilly et al. (2017) who reported increased testosterone concentrations in SAT microdialysate in PCOS women $(n=10)$ compared to healthy controls $(n=10)$.

We present the first study on the effects of insulin on AKR1C3 and CYP17A1 expression in PCOS-cultured adipocytes derived from SAT. Our non-PCOS data are consistent with that of O'Reilly et al. (2017) who confirmed the stimulatory effect of insulin $(20 \mathrm{nM})$ on the expression and activity of AKR1C3 and CYP17A1 mRNA in cultured subcutaneous adipocytes from non-PCOS women $(n=3)$.

With regards to our PI-3K data, there have been no previous studies on adipocytes. When compared with data from the ovary, our results are consistent with one study showing that insulin-mediated steroidogenesis in granulosa cell culture was not inhibited by PI-3K inhibitor (wortmannin) (Poretsky et al. 2001). In contrast, our data disagree with another study on theca cells suggesting $\mathrm{PI}-3 \mathrm{~K}$ as a possible mediator for the insulin stimulatory effects on CYP17 mRNA expression or activity (Munir et al. 2004). Further studies are therefore required to address this uncertainty.

We present the first data on insulin/LH interactions in adipose tissue. Our findings are consistent with one study on theca cells showing that insulin alone is capable of stimulating testosterone production in women with and without PCOS (Nestler et al. 1998). In contrast, our data disagree with another study on cultured theca cells reporting that insulin requires LH-induced cAMP activation to stimulate CYP17 activity (Munir et al. 2004).

The lack of any stimulatory effects of insulin/LH on androgen production in PCOS adipocytes was surprising. The exact explanation of this phenomenon remains uncertain. It is tempting to postulate that the high androgen levels in PCOS adipocytes may have reached a plateau level beyond which they cannot be augmented any further. However, our data do not support this hypothesis as insulin at high concentration $(100 \mathrm{nM})$ increased $A K R 1 C 3$ and testosterone in non-PCOS adipocytes to levels higher than those of PCOS adipocytes. This suggests that PCOS AKR1C3 and testosterone are 'potentially' not at a plateau. Another possible mechanism is the presence of a defect in insulin/LH receptors in PCOS adipocytes affecting their sensitivity to insulin/LH. This is supported by previous in vitro studies reporting post-binding defect in insulin signal transduction in PCOS adipocytes in 
relation to glucose uptake (Ciaraldi et al. 1992, DiamantiKandarakis \& Dunaif 2012). This defect has been attributed to serine phosphorylation of the insulin receptor and insulin receptor substrate-1 (IRS-1) secondary to increased intracellular serine kinases (Dunaif et al. 1995, Li et al. 2002, Baillargeon 2007). The increase in serine kinases has also been implicated in serine phosphorylation of CYP17, which is known to increase its 17,20-lyase activity with subsequent increase in androgen production. In other words, the same serine kinase, which inhibits insulin signalling, may also increase androgen production in PCOS (Diamanti-Kandarakis \& Dunaif 2012).

The apparent discrepancy between the levels of mRNA and protein expressions of AKR1C3 and CYP17A1 in PCOS vs non-PCOS SAT could be due to the small numbers included in the WB experiment. Another possible explanation of the lack of mRNA-protein correlation could be due to the highly variable protein half-life ranging from a few seconds to several days possibly due to variation in protein stability or post-translational processing as well as RNA-silencing mechanisms (Greenbaum et al. 2003, Beyer et al. 2004, Wu et al. 2008, Maier et al. 2009).

One limitation of our study is the lack of sufficient data on the protein expression of the androgen-synthesizing enzymes in SAT. Furthermore, we did not assess if the increased testosterone production in PCOS subcutaneous adipocyte culture is directly linked to $A K R 1 C$ or $C Y P 17 A 1$ activity. However, evidence for this link has been provided by O'Reilly et al. (2017) who reported that inhibition of AKR1C3 activity by 3,4-trifluoromethyl-phenylaminobenzoic acid resulted in the reduction of testosterone generation from primary subcutaneous adipocytes obtained from healthy (non-PCOS) women.

Our study has provided an important and new insight into the subcutaneous adipose tissue dynamics that may contribute to the pathogenesis and pathophysiology of PCOS. Our data support the hypothesis that SAT could be an important source of PCOS-related hyperandrogenaemia. The markedly higher testosterone levels in PCOS adipocytes seem to be independent of weight as both groups were weight matched. Our data suggest that excess androgen production in subcutaneous adipocytes is not directly caused by PCOS-related hyperinsulinaemia. We also confirm that insulin and LH can each independently stimulate SAT androgen production in healthy women and there is no synergism between them.

In conclusion, subcutaneous adipose tissue of PCOS women produces increased amounts of androgen, which is not directly linked to inulin or LH. This suggests that
SAT is an important contributor to the PCOS-related hyperandrogenaemia.

\section{Declaration of interest}

The authors declare that there is no conflict of interest that could be perceived as prejudicing the impartiality of the research reported.

\section{Funding}

This study was supported by a PhD Scholarship from the Libyan Government offices.

\section{Authors' contribution statement}

S Amer: Conception of the idea, study design, recruitment, obtaining the fat biopsies, interpretation of results and writing the manuscript. N Alzanati: Laboratory work, data collection, statistical analysis and manuscript review. A Warren: Lab experiment especially adipocyte culture and Western blot and manuscript review. R Tarbox: Lab experiments especially PCR and manuscript review. R Khan: Supervisor of the laboratory work, validation of laboratory techniques, review of all lab results, writing up and reviewing the manuscript.

\section{Acknowledgements}

The authors are grateful to all participants and to all clinical and lab staff who have helped with this study. They are also grateful to the Libyan Government offices for their financial support.

\section{References}

Baillargeon JP 2007 Insulin action in polycystic ovary syndrome: in vivo and in vitro. In The Polycystic Ovary Syndrome-Current Concepts on Pathogenesis and Clinical Care, pp 43-68. Ed R Azziz. New York, NY, USA: Springer Publishing. (https://doi.org/10.1007/978-0-387-692487_4)

Beyer A, Hollunder J, Nasheuer HP \& Wilhelm T 2004 Posttranscriptional expression regulation in the yeast Saccharomyces cerevisiae on a genomic scale. Molecular and Cellular Proteomics 3 1083-1092. (https:// doi.org/10.1074/mcp.M400099-MCP200)

Blouin K, Blanchette S, Richard C, Dupont P, Luu-The V \& Tchernof A 2005 Expression and activity of steroid aldoketoreductases $1 \mathrm{C}$ in omental adipose tissue are positive correlates of adiposity in women. American Journal of Physiology: Endocrinology and Metabolism 288 E398-E404. (https://doi.org/10.1152/ajpendo.00312.2004)

Bremer AA \& Miller WL 2008 The serine phosphorylation hypothesis of polycystic ovary syndrome: a unifying mechanism for hyperandrogenemia and insulin resistance. Fertility and Sterility 89 1039-1048. (https://doi.org/10.1016/j.fertnstert.2008.02.091)

Cadagan D, Khan R \& Amer S 2014 Female adipocyte androgen synthesis and the effects of insulin. Molecular Genetics and Metabolism Reports 29 254-263. (https://doi.org/10.1016/j.ymgmr.2014.05.002)

Ciaraldi TP, el-Roeiy A, Madar Z, Reichart D, Olefsky JM \& Yen SS 1992 Cellular mechanisms of insulin resistance in polycystic ovarian syndrome. Journal of Clinical Endocrinology and Metabolism $\mathbf{7 5}$ 577-583. (https://doi.org/10.1210/jcem.75.2.1322430) 
Dalla Valle L, Toffolo V, Nardi A, Fiore C, Bernante P, Di Liddo R, Parnigotto PP \& Colombo L 2006 Tissue-specific transcriptional initiation and activity of steroid sulfatase complementing dehydroepiandrosterone sulfate uptake and intracrine steroid activations in human adipose tissue. Journal of Endocrinology 190 129-139. (https://doi.org/10.1677/joe.1.06811)

Diamanti-Kandarakis E \& Dunaif A 2012 Insulin resistance and the polycystic ovary syndrome revisited: an update on mechanisms and implications. Endocrine Reviews 33 981-1030. (https://doi org/10.1210/er.2011-1034)

Dunaif A, Xia J, Book CB, Schenker E \& Tang Z 1995 Excessive insulin receptor serine phosphorylation in cultured fibroblasts and in skeletal muscle. A potential mechanism for insulin resistance in the polycystic ovary syndrome. Journal of Clinical Investigation 96 801-810. (https:// doi.org/10.1172/JCI118126)

Elhassan YS, Idkowiak J, Smith K, Asia M, Gleeson H, Webster R, Arlt W \& O'Reilly MW 2018 Causes, patterns, and severity of androgen excess in 1205 consecutively recruited women. Journal of Clinical Endocrinology and Metabolism 103 1214-1223. (https://doi. org/10.1210/jc.2017-02426)

Fauser BC, Tarlatzis BC, Rebar RW, Legro RS, Balen AH, Lobo R, Carmina E, Chang J, Yildiz BO, Laven JS, et al. 2012 Consensus on women's health aspects of polycystic ovary syndrome (PCOS): the Amsterdam ESHRE/ASRM-Sponsored. 3rd PCOS Consensus Workshop Group. Fertility and Sterility 97 28-38.e25. (https://doi.org/10.1016/j. fertnstert.2011.09.024)

Feher T \& Bodrogi L 1982 A comparative study of steroid concentrations in human adipose tissue and the peripheral circulation. Clinica Chimica Acta 126 135-141. (https://doi.org/10.1016/00098981(82)90029-8)

Gilling-Smith C, Story H, Rogers V \& Franks S 1997 Evidence for a primary abnormality of thecal cell steroidogenesis in the polycystic ovary syndrome. Clinical Endocrinology 47 93-99. (https://doi. org/10.1046/j.1365-2265.1997.2321049.x)

Greenbaum D, Colangelo C, Williams K \& Gerstein M 2003 Comparing protein abundance and mRNA expression levels on a genomic scale. Genome Biology 4 117. (https://doi.org/10.1186/gb-2003-4-9-117)

Kinoshita T, Honma S, Shibata Y, Yamashita K, Watanabe Y, Maekubo H, Okuyama M, Takashima A \& Takeshita N 2014 An innovative LC-MS/ MS-based method for determining CYP 17 and CYP 19 activity in the adipose tissue of pre- and postmenopausal and ovariectomized women using 13C-labeled steroid substrates. Journal of Clinical Endocrinology \& Metabolism 99 1339-1347. (https://doi.org/10.1210/ jc.2013-3715)

Kirschner MA, Samojlik E, Drejka M, Szmal E, Schneider G \& Ertel N 1990 Androgen-estrogen metabolism in women with upper body versus lower body obesity. Journal of Clinical Endocrinology and Metabolism 70 473-479. (https://doi.org/10.1210/jcem-70-2-473)

Kousta E, White DM, Cela E, McCarthy MI \& Franks S 1999 The prevalence of polycystic ovaries in women with infertility. Human Reproduction 14 2720-2723. (https://doi.org/10.1093/ humrep/14.11.2720)

Kumar A, Woods KS, Bartolucci AA \& Azziz R 2005 Prevalence of adrenal androgen excess in patients with the polycystic ovary syndrome (PCOS). Clinical Endocrinology 62 644-649. (https://doi.org/10.1111/ j.1365-2265.2005.02256.x)

Lauritsen MP, Bentzen JG, Pinborg A, Loft A, Forman JL, Thuesen LL, Cohen A, Hougaard DM \& Nyboe Andersen A 2014 The prevalence of polycystic ovary syndrome in a normal population according to the Rotterdam criteria versus revised criteria including anti-Müllerian hormone. Human Reproduction 29 791-801. (https://doi.org/10.1093/ humrep/det469)

Li M, Youngren JF, Dunaif A, Goldfine ID, Maddux BA, Zhang BB \& Evans JL 2002 Decreased insulin receptor (IR) autophosphorylation in fibroblasts from patients with PCOS: effects of serine kinase inhibitors and IR activators. Journal of Clinical Endocrinology and Metabolism 87 4088-4093. (https://doi.org/10.1210/jc.2002-020363)

Li Y, Li Y, Yu Ng EH, Stener-Victorin E, Hou L, Wu T, Han F \& Wu X 2011 Polycystic ovary syndrome is associated with negatively variable impacts on domains of health-related quality of life: evidence from a meta-analysis. Fertility and Sterility 96 452-458. (https://doi. org/10.1016/j.fertnstert.2011.05.072)

Mackenzie SM, Hudat SS, Sattar N, Fraser R, Connell JMC \& Davies E 2008 Depot-specific steroidogenic gene transcription in human adipose tissue. Clinical Endocrinology 69 848-854. (https://doi. org/10.1111/j.1365-2265.2008.03262.x)

Maier T, Güell M \& Serrano L 2009 Correlation of mRNA and protein in complex biological samples. FEBS Letters 583 3966-3973. (https://doi. org/10.1016/j.febslet.2009.10.036)

Munir I, Yen HW, Geller DH, Torbati D, Bierden RM, Weitsman SR, Agarwal SK \& Magoffin DA 2004 Insulin augmentation of 17alphahydroxylase activity is mediated by phosphatidyl inositol 3-kinase but not extracellular signal-regulated kinase-1/2 in human ovarian theca cells. Endocrinology 145 175-183. (https://doi.org/10.1210/ en.2003-0329)

Nestler JE, Jakubowicz DJ, de Vargas AF, Brik C, Quintero N \& Medina F 1998 Insulin stimulates testosterone biosynthesis by human thecal cells from women with polycystic ovary syndrome by activating its own receptor and using inositolglycan mediators as the signal transduction system. Journal of Clinical Endocrinology and Metabolism 83 2001-2005. (https://doi.org/10.1210/jcem.83.6.4886)

O'Reilly MW, Kempegowda P, Walsh M, Taylor AE, Manolopoulos KN, Allwood JW, Semple RK, Hebenstreit D, Dunn WB, Tomlinson JW, et al. 2017 AKR1C3-mediated adipose androgen generation drives lipotoxicity in women with polycystic ovary syndrome. Journal of Clinical Endocrinology and Metabolism 102 3327-3339. (https://doi. org/10.1210/jc.2017-00947)

Poretsky L, Seto-Young D, Shrestha A, Dhillon S, Mirjany M, Liu HC, Yih MC \& Rosenwaks Z 2001 Phosphatidyl-inositol-3 kinaseindependent insulin action pathway(s) in the human ovary. Journal of Clinical Endocrinology and Metabolism 86 3115-3119. (https://doi. org/10.1210/jcem.86.7.7617)

Puche C, Jose M, Cabero A \& Meseguer A 2002 Expression and enzymatic activity of the P450c17 gene in human adipose tissue. European Journal of Endocrinology 146 223-229. (https://doi.org/10.1530/ eje.0.1460223)

Quinkler M, Sinha B, Tomlinson JW, Bujalska IJ, Stewart PM \& Arlt W 2004 Androgen generation in adipose tissue in women with simple obesity - a site-specific role for 17beta-hydroxysteroid dehydrogenase type 5. Journal of Endocrinology 183 331-342. (https://doi.org/10.1677/ joe.1.05762)

Rosenfield RL, Mortensen M, Wroblewski K, Littlejohn E \& Ehrmann DA 2011 Determination of the source of androgen excess in functionally atypical polycystic ovary syndrome by a short dexamethasone androgen-suppression test and a low-dose ACTH test. Human Reproduction 26 3138-3146. (https://doi.org/10.1093/ humrep/der291)

Rotterdam ESHRE/ASRM-Sponsored PCOS Consensus Workshop Group 2004 Revised 2003 consensus on diagnostic criteria and long-term health risks related to polycystic ovary syndrome (PCOS). Human Reproduction 19 41-47. (https://doi.org/10.1093/humrep/deh098)

Samojlik E, Kirschner MA, Silber D, Schneider G \& Ertel NH 1984 Elevated production and metabolic clearance rates of androgens in morbidly obese women. Journal of Clinical Endocrinology and Metabolism 59 949-954. (https://doi.org/10.1210/jcem-59-5-949)

Vandesompele J, De Preter K, Pattyn F, Poppe B, Van Roy N, De Paepe A \& Speleman F 2002 Accurate normalization of real-time quantitative RT-PCR data by geometric averaging of multiple internal control genes. Genome Biology 3 RESEARCH0034.1-0034.11 (https://doi. org/10.1186/gb-2002-3-7-research0034) https://joe.bioscientifica.com

https://doi.org/10.1530/JOE-18-0674 (c) 2019 Society for Endocrinology Published by Bioscientifica Ltd. Printed in Great Britain 
Wang L, Li S, Zhao A, Tao T, Mao X, Zhang P \& Liu W 2012 The expression of sex steroid synthesis and inactivation enzymes in subcutaneous adipose tissue of PCOS patients. Journal of Steroid Biochemistry and Molecular Biology 132 120-126. (https://doi. org/10.1016/j.jsbmb.2012.02.003)

Wu G, Nie L \& Zhang W 2008 Integrative analyses of posttranscriptional regulation in the yeast Saccharomyces cerevisiae using transcriptomic and proteomic data. Current Microbiology 57 18-22. (https://doi. org/10.1007/s00284-008-9145-5)

Zhang LH, Rodriguez H, Ohno S \& Miller WL 1995 Serine phosphorylation of human P450c17 increases 17,20-lyase activity: implications for adrenarche and the polycystic ovary syndrome. PNAS 92 10619-1023. (https://doi.org/10.1073/ pnas.92.23.10619)

Received in final form 12 February 2019

Accepted 25 February 2019

Accepted Preprint published online 25 February 2019
(C) 2019 Society for Endocrinology Published by Bioscientifica Ltd.
Printed in Great Britain 